\title{
La educación superior y la categoría condición humana: Por una visión integradora
}

\author{
Higher Education and the Human Condition Category: For an Integrative Vision
}

A educação superior e a categoria condição humana: por uma visão integradora



\author{
Freddy Varona-Domínguez \\ Universidad de La Habana, \\ Centro de Estudios para el Perfeccionamiento de la Educación Superior \\ La Habana, Cuba \\ fvarona@cepes.uh.cu \\ http://orcid.org/0000-0002-5214-2735
}

Recibido • Received • Recebido: 29 / 04 / 2019
Corregido • Revised • Revisado: 21 / 10 / 2020
Aceptado • Accepted • Aprovado: 14 / 12 / 2020

Resumen: La temática central de este ensayo es la necesidad de desplegar en la educación superior la visión integradora. El punto de partida es la exigencia del desarrollo científico-tecnológico de la formación de profesionales con una visión que integre saberes, la cual entra en contradicción con la mirada que reduce y fracciona, aún dominante en la educación superior. La base conceptual es el pensamiento complejo y la categoría condición humana. Entre las ideas que se desarrollan están: el valor de la categoría condición humana para desplegar la visión integradora en la educación superior; la lucha contra el modo de concebir la educación superior como una empresa; la importancia de lo afectivo en la educación superior. El objetivo es argumentar algunas manifestaciones en la educación superior del pensamiento que fragmenta y reduce. Entre las conclusiones están: La visión integradora en la educación superior impide que se sobrevalore la formación profesional y es poderosa para rebasar el racionalismo extremo y abrirse a la afectividad.

Palabras claves: Educación superior; complejidad; reducción; disyunción; afectividad; indiferencia; condición humana.

Abstract: The central theme of this essay is the need to deploy an integrative vision in higher education. The starting point is the requirement of scientific-technological development that professionals be trained with a vision that integrates knowledge, which contradicts the view that reduces and divides and still prevails in higher education. The conceptual base is complex thinking and the human condition category. Among the ideas developed are the value of the human condition category to deploy the integrative vision in higher education, the fight against the way of conceiving higher education as a business, and the importance of the affective dimension in higher education. The objective is to argue some manifestations of fragmentary and reductionist thought in higher education. One of the conclusions is that the integrative vision in higher education prevents 
http://doi.org/10.15359/ree.25-1.24

http://www.una.ac.cr/educare

educare@una.ac.cr

professional training from being overvalued and is powerful to overcome extreme rationalism and open up to affectivity. Among the conclusions is that higher education's integrative vision prevents professional training from being overvalued and is powerful in overcoming extreme rationalism and opening up to affectivity.

Keywords: High education; complexity; reduction; disjunction; affectivity; indifference; human condition.

Resumo: O tema central deste ensaio é a necessidade de implantar uma visão integradora no ensino superior. O ponto de partida é a exigência do desenvolvimento científico-tecnológico de que os profissionais sejam formados com uma visão integradora de saberes, o que está em contradição com a visão que reduz e divide que ainda domina o ensino superior. A base conceitual é o pensamento complexo e a categoria condição humana. Entre as ideias que se desenvolvem estão: o valor da categoria condição humana para implantar a visão integrativa no ensino superior; a luta contra a forma de conceber o ensino superior como negócio; a importância do afetivo no ensino superior. O objetivo é discutir algumas manifestações na educação superior de um pensamento que se fragmenta e se reduz. Entre as conclusões: A visão integradora no ensino superior evita que a formação profissional seja supervalorizada; é poderosa para superar o racionalismo e se abrir à afetividade.

Palavras-chave: Educação superior; complexidade; redução; disjunção; afetividade; indiferença; condicion humana.

\section{Introducción}

La profunda revolución científica y tecnológica que se despliega desde mediados de la vigésima centuria ha dotado a los seres humanos de una capacidad superior para modificar los procesos naturales e incluso para transformarse a sí mismos, a su vez, ha generado una cantidad gigantesca de información, que crece de manera asombrosa y permite la consolidación de una serie de saberes, como la microelectrónica, las biotecnologías, entre otros, los cuales han abierto las puertas a lo que hasta hace poco tiempo era una quimera o una ficción fruto de una fantasía muy creativa. Sobre esta base, en el siglo XXI es cada vez más notoria la importancia del conocimiento, particularmente del científico y el tecnológico, no solo para elevar el nivel de vida de los seres humanos, hacer mayores sus grados de satisfacción o extender la duración de su existencia, sino también para estar preparados a fin de poder enfrentar contingencias como la pandemia covid-19. El grado óptimo de estos propósitos no se logra con un modo de pensar simplificador, que fracciona y separa, sino con uno complejo e integrador.

La educación superior está en el centro de tal revolución, pero esta característica no ha conducido persea que, de manera general, en ella se haya superado stricto sensu el modo de pensar que reduce y fragmenta, y que, por consiguiente, haya llegado a predominar el pensamiento complejo e integrador, acorde al desarrollo científico y tecnológico actual. Esta insuficiencia se deja observar, por ejemplo, cuando quienes se gradúan no satisfacen plenamente las exigencias de la sociedad, entre cuyas causas puede estar el predominio en el profesorado de una visión 
http://doi.org/10.15359/ree.25-1.24

reduccionista y fraccionadora, como sucede en cuanto a la sobrevaloración de la preparación laboral del estudiantado o de su capacidad racional en detrimento de la afectividad.

Una vía para lograr que en la educación superior avance la visión integradora es el estudio y la aplicación del pensamiento complejo. Para este fin tiene una gran importancia la concepción compleja del ser humano, a través de la cual se concibe como una totalidad. Con esta finalidad pueden ser útiles diversas teorías y categorías que pueden emplearse con un razonamiento crítico. Así puede suceder con la categoría condición humana según la comprensión de la autora alemana Hannah Arendt (1906-1975), con la cual destacaba que todo cuanto tiene relaciones con el ser humano condiciona su existencia como ser humano; de ahí que al tenerla en cuenta en la educación superior se enfatiza que esta debe abarcar al ser humano en su totalidad y con todos los nexos en los cuales existe. Desde esta perspectiva se cierran las posibilidades a la fragmentación y el reduccionismo que tienen lugar cuando se piensa que la educación superior solo ha de atender las cualidades laborales del estudiantado o cuando de este se reconoce como valiosa únicamente la capacidad racional. Estos asuntos constituyen el núcleo del presente trabajo. Valga apuntar, desde el inicio, que el pensamiento complejo no niega categóricamente la fragmentación, ni la separación, pero sí que se conciban como un absoluto.

El combate al predominio en la educación superior del pensamiento que reduce, fragmenta y separa, y el empleo con tal finalidad de la categoría condición humana, exigen el despliegue, sin limitaciones, de la creatividad, sobre todo en cuanto a la búsqueda de procedimientos y métodos que contribuyan a realizar dicho propósito, lo cual debe atenderse desde todas las perspectivas y con todos los medios. En este caso está la redacción y publicación de textos donde se reflexione sobre esta temática, se critiquen los extremismos y se expongan criterios y soluciones, a fin de incentivar el debate científico.

Esas consideraciones toman un matiz más llamativo si se tiene en cuenta que, como afirman los autores Wee y Monarca (2019), ante la educación superior (docencia, investigación y extensión) existen diversas tendencias que se mueven entre la democratización de los espacios públicos y el acceso al conocimiento, por un lado, y su mercantilización, por el otro; que existen diversos estudios acerca del proceso mediante el cual dicha educación se ha acomodado a las exigencias de un modelo mercantilista o le hace resistencia, y que el nivel educacional más elevado "parece estar perdiendo poco a poco su función social y comienza a integrarse rápidamente en una nueva racionalidad económica" (p. 131). A propósito de estos tópicos, vale repensar el papel de la educación superior como formadora de profesionales y como formadora de ciudadanía. Vale acotar que entre estas dos aristas no tiene que haber discrepancias, basta que haya una visión integradora, capaz de vencer al pensamiento que simplifica, fracciona y reduce. La categoría condición humana es de gran valía para contribuir a dilucidar este asunto. 
http://doi.org/10.15359/ree.25-1.24

http://www.una.ac.cr/educare

educare@una.ac.cr

Sobre la base de la categoría condición humana y desde la perspectiva del pensamiento complejo, el objetivo de este trabajo es argumentar algunas manifestaciones en la educación superior del pensamiento que fragmenta y reduce. La bibliografía está formada por artículos y libros, muchos de reciente publicación y otros considerados clásicos de estos temas, como Los siete saberes necesarios para la educación del futuro (Morin, 1999), La cabeza bien puesta. Repensar la reforma. Reformar el pensamiento (Morin, 2002) y La condición humana (Arendt, 2005).

\section{Desarrollo}

Hoy es imposible escribir un texto y no mencionar, aunque sea de soslayo, la pandemia covid-19, con sus daños, sobre todo las irreparables pérdidas de miles de vidas humanas, y con los desafíos que ha puesto ante la humanidad en cuanto a la preparación científica, tecnológica y de organización social para enfrentar epidemias, catástrofes y males globales de diversos tipos y magnitudes similares o mayores, a fin de evitar muertes y las secuelas espirituales que dejan, así como daños materiales y consecuencias nefastas para la existencia del planeta. El ser humano saldrá triunfante de esta encrucijada gracias, ante todo, al personal dedicado a los asuntos científicos y tecnológicos, no solo por su preparación profesional, conocimientos y capacidad racional, sino también por sus valores morales y por la carga sentimental y pasional que dedique a tamaña faena.

El gigantesco desarrollo de la ciencia y la tecnología, que sostiene ese optimismo, a su vez influye en todos los sentidos en la educación superior $y$, por tanto, condiciona muchos de los cambios que se suceden en ella. En esta vorágine es básico tener presente, en todo momento, que quienes se están educando son seres humanos y no solo profesionales en ciernes y, por lo tanto, son entes racionales y afectivos en quienes hay que despertar el interés tanto por la profesión, como por la sociedad donde viven.

\section{El ser humano a la luz de dos modos de pensar}

Hay dos afirmaciones que, por archiconocidas, puede parecer innecesario recordarlas: una, el ser humano es el objeto de la educación; y la otra, todo el quehacer educativo siempre se basa en una concepción acerca del ser humano. Ahora bien, ambas aseveraciones son, en gran medida, las que permiten entender por qué toda labor educativa es tan compleja, como teoría y como práctica.

A la hora de hablar del ser humano sale a relucir una interrogante que ha motivado durante siglos a la filosofía y a otras disciplinas del pensamiento: ¿cuál es la esencia humana? Muchas y variadas han sido las respuestas; no obstante, se pueden agrupar en dos grandes 
http://doi.org/10.15359/ree.25-1.24

campos, aun cuando esta clasificación no se caracterice por una pureza ciento por ciento. Uno de ellos pertenece al pensamiento o paradigma simplificador y disyuntivo, mientras que el otro corresponde al pensamiento o paradigma complejo e integrador.

La primera variante, que fracciona y separa, es propia de la Modernidad (siglo XVII-primera mitad siglo XX) y tiene en el filósofo y matemático francés Renato Descartes (1696-1650) a uno de sus grandes iniciadores, quien, guiado por el propósito de lograr la mayor profundidad en la cognición, concluyó que era conveniente separar y simplificar. Desde esta perspectiva desplegó grandes elaboraciones teóricas, apoyadas en una afirmación que constituye un principio de sus ideas y del paradigma que inauguró: la razón es la "característica del hombre, en cuanto por ella nos diferenciamos de las bestias" (Descartes, 2011, p. 161), por tanto, es la única propiedad humana que reconoce como valiosa para la ciencia.

Guiados por esa y otras aserciones cartesianas, a lo largo de la Modernidad se desarrollaron teorías e investigaciones de las más disímiles especialidades y afiliaciones; esta modalidad no fue la única durante este período, pero fue la que predominó y todavía existen grupos partidarios suyos, muchos de ellos seguidores del positivismo, filosofía que a partir de mediados del siglo XIX comenzó a tener un lugar relevante en este paradigma.

Entre las características del pensamiento simplificador están las siguientes: este modo de pensar se concibe como el único método científico y con funcionalidad para todo tipo de conocimiento; la base y guía del desarrollo científico son las ciencias naturales; el propósito final es dominar la naturaleza; para la ciencia son imprescindibles la neutralidad y la objetividad, por tanto, al conocimiento científico son ajenos los sujetos cognoscentes con sus valores y otras características, como las emociones, los sentimientos y las pasiones.

A pesar de sus limitaciones, el pensamiento simplificador y disyuntivo le ha permitido a la humanidad obtener grandes resultados. Además, la simplificación y la separación no son errores de la humanidad, el ser humano a lo largo de la historia ha recurrido a esos modos para aprehender, con la mayor profundidad a su alcance, lo que desea conocer, lo cual "no ha sido causada de manera exclusiva por factores cognitivos, sino condicionada también por factores de carácter social e inclusive de orden ideológico" (Guadarrama, 2018, p. 19). A propósito de estas reflexiones, vale incluir la afirmación siguiente del autor Luengo González (2016): "El riesgo no está en la simplificación, sino en el hecho de quedarse con ella como fin, como si en eso consistiera el propósito final del conocimiento" (p. 64). En toda faena humana es necesario simplificar, separar, analizar, pero vale complementarlos con el todo, la integración y la síntesis.

Desde mediados del siglo XX, el desarrollo de la ciencia y la tecnología ha ido conduciendo a tomar conciencia de la necesidad de incorporar otro tipo de pensamiento, complejo (Morin, 2002) e integrador (Maldonado, 1999). Esta variante, entre otros aspectos, permite comprender que el ser humano es de suma complejidad, porque es la integración de múltiples relaciones 
http://doi.org/10.15359/ree.25-1.24

http://www.una.ac.cr/educare

educare@una.ac.cr

donde se entrecruzan diversos caracteres, incluso antagónicos (Morin, 1999). Visto desde esta perspectiva, el ser humano es un sistema donde no solo la razón es importante para el conocimiento, sino también la afectividad.

El autor Ferrada-Sullivan (2017) subraya que en la educación superior este tipo de pensamiento vincula sujetos y objetos, destaca de los contextos lo multidimensional y relacional y enfatiza que esto mismo hace posible "entrelazar y entrecruzar una serie de condiciones biológicas, antropológicas, culturales, ambientales y creativas constituyentes del fenómeno de la vida" (p. 9). Con la visión compleja e integradora se elimina la posibilidad de concebir al estudiantado de manera fraccionada y hacer así un absoluto de alguna característica. Para ello es preciso, como deja entrever el autor Castañeda Bustamante (2018), abrirles el paso a las nuevas ideas, aunque sea para criticarlas.

Ese modo de pensar está presente en la categoría condición humana, aunque no es creación del pensamiento complejo; ha sido trabajada de diversas maneras, sobre todo por la filosofía, y por lo general relacionada con la esencia y la naturaleza humanas (Riechmann, 2014), aunque Aldana Contardi (2012) y Andrés Roig (2003) aseguran que las excede. Este criterio es aplicable a la definición de condición humana elaborada por Hannah Arendt, que es la que se emplea en este texto.

\section{La categoría condición humana frente a la fragmentación en la educación superior}

En los estudios acerca de Hannah Arendt la mayor atención no recae sobre la categoría de referencia, pues de su pensamiento han sido más estudiadas las posiciones políticas (Pallarès Piquer y Muñoz Escalada, 2017; Zapata, 2006), porque son básicas en sus ideas; además, de estas, el núcleo es la actividad (Comesaña Santalices y Cure de Montiel, 2006) y es en esta última donde ubica la política como mediadora entre el ser humano y su entorno (Korstanje, 2014). Desde esta perspectiva reflexiona en torno a la autoridad y sus nexos con la educación (Nieves Loja, 2017), tema valioso respecto a la educación superior.

Entre las interpretaciones del pensamiento de Arendt destacan las de la autora Billitteri (2018), de quien apunta la oposición a "una pedagogía únicamente interesada en las competencias útiles por el mercado" (p. 120), y las del autor Riechmann (2014), que destaca en la concepción de la alemana el rasgo básico es "la pluralidad humana con su doble carácter: igualdad y diferencia" (p. 260); esta característica también está presente en los razonamientos de la autora Barrio (2015) que expone, mediante las elaboraciones de la pensadora, acerca de los vínculos entre el pensamiento y el discurso.

Para Arendt (2005), la condición humana es "todo lo que entra en el mundo humano por su propio acuerdo o se ve arrastrado a él por el esfuerzo del hombre" (p. 23), o sea, lo que hace 
http://doi.org/10.15359/ree.25-1.24

que los seres humanos sean seres humanos y no otro ser. Un gran mérito es la complejidad que apunta al referir las condiciones que posibilitan la vida humana, es decir, todo con lo cual los seres humanos entran en contacto, que de inmediato se convierte en una condición de su existencia, así como "las cosas que deben su existencia exclusivamente a los hombres condicionan de manera constante a sus productores humanos" (Arendt, 2005, p. 23): un condicionamiento mutuo entre los seres humanos y lo que crean.

Sibien a la luz del pensamiento complejo se concibe al serhumano como una totalidad y una integración de aspectos diversos y contrapuestos, donde no tienen cabida su fraccionamiento y separación, la categoría condición humana destaca la integración entre el ser humano y todo lo que hace posible su existencia y desarrollo. Es en estos nexos donde tiene lugar la educación superior, que de modo progresivo está presente en todas en todas las relaciones sociales; estas son componentes de la condición humana, pero es ella donde dichas relaciones se revelan, reafirman, reproducen, alteran. Al pensarse la educación superior a través de esta categoría se ve con más claridad el daño, si se concibe de modo fraccionado y reduccionista. Esta afirmación no es una novedad, pero no siempre se atiende con el esmero que merece; es preciso insistir en ella, y hacerlo desde diversas perspectivas.

\section{La categoría condición humana ante la sobrevaloración delas cualidades profesionales}

Hoy la vida, con más insistencia que en cualquier época pasada, demuestra que la educación superior debe ser multilateral y armónica. Esta posición, que puede verse como un principio, es la negación de los reduccionismos y los fraccionamientos inconexos e injustificables y tiene como base y punto de partida, los nexos entre la educación superior, la ciencia y la tecnología, los cuales son cada vez más variados, profundos y fuertes. El desarrollo científico y tecnológico actual demanda profesionales con una preparación cada vez mayor, y es la educación superior la que, en gran medida, puede satisfacer esta exigencia. Ahora bien, si se tiene en cuenta la diversidad y riqueza en todos los sentidos del mencionado desarrollo, para cumplir con estas características, no basta que quienes se gradúen en la universidad dominen la especialidad. La sociedad actual pone ante cada hombre y mujer situaciones que requieren variedad de conocimientos e integración de estos mismos, no solo para resolverlas, sino también para entenderlas. A tomar conciencia de este requisito de hoy pueden contribuir la concepción compleja del ser humano y, sobre todo, la categoría condición humana.

Aunque la necesidad antes expuesta es cada vez más notoria, todavía es evidente la visión fraccionada y reduccionista en la educación superior, lo cual se debe, entre otras causas, a que se observa desde la perspectiva empresarial y mercantil. De esta forma se entiende como "un apéndice de la industria y los profesores deben comportarse como emprendedores 
http://doi.org/10.15359/ree.25-1.24

http://www.una.ac.cr/educare

educare@una.ac.cr

o vendedores" (Bermúdez-Aponte y Laspalas Pérez, 2017, p. 113), se intensifica el afán de que responda a las exigencias del mercado y que se transforme en una empresa, con lo cual se daña su sentido educativo (Güechá Hernández, 2018), el estudiantado se cosifica como una mercancía, porque se ve está destinado a brindar un servicio, y el personal docente e investigador compite entre sí por conseguir recursos para sus actividades. Al mismo tiempo, la educación superior se privatiza y el acceso a ella se reduce a quienes pueden pagarla, se centra en la rentabilidad y el éxito individual (Ardila-Muñoz, 2016) y se intensifica el menosprecio a las humanidades y las ciencias sociales, porque se opina que no son rentables (Monge Ortiz, 2020).

Hay estudios en los cuales de ese fenómeno se deslindan ventajas y desventajas, como los de García Mazo (2018) que ubica en lo positivo la articulación entre el sector educativo y el productivo, y entre lo negativo, la incorporación al país de instituciones extranjeras de dudosas calidad y pertinencia, y, con ello, el cierre de universidades públicas, así como daños a la cultura y a la identidad cultural.

Desde la perspectiva mercantil y empresarial se considera que proporcionar competencias y habilidades profesionales es el objetivo central de la educación superior (Brower Beltramin, 2014). Este propósito no sería objeto de atención especial en el presente trabajo, si no atentara contra la amplitud que la sociedad de hoy le exige a la educación superior, y contra la condición humana, cuya esencia no está dada únicamente por la preparación que se posea para trabajar. Al subordinarse a los mandatos mercantiles y al pretenderse, por encima de otros deberes, satisfacer las exigencias de los posibles puestos laborales y del mercado, el quehacer educativo se restringe a lo profesional y así se hiperboliza el componente laboral de la educación superior.

El núcleo del asunto radica en que si se limita solo a las cualidades profesionales (lo cual es una tarea sumamente complicada y de crecientes exigencias, además, a la que no se le debe restar importancia, pero tampoco sobrevalorar) queda incompleta la misión de la educación superior, que es educar al ser humano en la integridad históricamente alcanzable, es decir, en sus múltiples relaciones sociales y no solo las laborales. Si solo se atiende el componente profesional, otras áreas del quehacer educativo quedan excluidas.

Una de las grandes tareas que tiene hoy el profesorado de la educación superior es enseñar al alumnado a orientarse en la enorme cantidad de información existente y a entender que esta es un medio para lograr un fin: conocer con creciente profundidad la naturaleza y, también, al ser humano con todos los resultados de su creatividad. En correspondencia, debe motivar al estudiantado a investigar la raíz de los fenómenos y a aprender a valorar el conocimiento, no solo en su valor intrínseco, sino también en función del ser humano. De este modo, en la base de la concepción del proceso educativo y, particularmente de la orientación del trabajo investigativo, está la esencia de la categoría arendtiana condición humana y de la comprensión compleja del ser humano. No basta que un sujeto graduado solo tenga óptimas cualidades 
http://doi.org/10.15359/ree.25-1.24

profesionales; el profesorado debe entender esta limitación y no solo desde el ángulo de las necesidades de la sociedad, sino también porque atenta contra la amplitud consustancial a la condición humana.

A tales aspiraciones puede contribuir un aprendizaje complejo que, entre otros aspectos, requiere "la integración en el aprendiz de saberes científicos, cotidianos y profesionales, en un mismo escenario de formación y posterior ejercicio profesional" (Cuadra-Martínez et al., 2018, p. 20). Esto significa lograr una estrecha relación entre lo que el estudiantado aprende en la universidad y los desafíos que imponen los contextos sociales y laborales, cuya integración es decisiva para realizar el propósito de formar grupos profesionales reflexivos, creativos, eficientes, activos socialmente, integrales.

En el quehacer educacional, junto a la prioridad que merece la preparación científica, ha de ubicarse, como tarea de vital importancia, el componente ético. Entre ambas partes debe existir equilibrio. No existe la persona estudiosa imparcial. Cualquier reflexión y toda obra humana (incluida la de educación superior) porta un grado de responsabilidad con la sociedad, de compromiso con ella, por lo cual, la carga ética está siempre presente. De esta responsabilidad el profesorado debe ser consciente y lograr que sus estudiantes también lo sean, que lleguen a ser hombres y mujeres capaces de detectar los problemas sociales y solucionarlos. Es "orientar a la educación superior como espacio de diálogo inquebrantable al servicio de la sociedad" (Ávila Alexander, 2015, p. 102).

Para enfrentar el reduccionismo de referencia, es menester que en los conocimientos y habilidades que se reciben en la educación superior se incluyan otros de diversas índoles (morales, estéticos, políticos) para que en la sociedad quienes lleguen a ser profesionales de alta calidad constituyan, también, ciudadanos y ciudadanas de elevados valores (Llerena Companioni, 2015). Es necesario promover en el estudiantado su condición civil, esto es, desarrollar en él su capacidad de actor social, es decir, su interés por la sociedad y su preparación para participar activamente en ella, y hacerlo de manera reflexiva, creativa, crítica, que beneficie a la humanidad; para lograr este propósito es crucial que se fortalezca en el alumnado la percepción de la intersubjetividad y con ella la atención hacia los otros individuos, así como la comprensión de significados y de las características del lugar y del momento histórico (González Rivero, 2019). Esta labor no puede reducirse a un listado de contenidos docentes, ni a un número de conductas históricas a tomar como patrón o ejemplo; antes bien tiene que ser muy creativa y estar vinculada desde la base con las circunstancias sociales del momento y con los objetivos sociales a corto y mediano alcance.

La educación superior debe moldear todas las capacidades y facultades del alumnado, no únicamente para satisfacer las exigencias económicas o políticas, sino para avanzar en el difícil camino del mejoramiento humano, que, aunque se corresponde con lo alcanzable según las condiciones históricas, al mismo tiempo constituye un impulso para avanzar a niveles superiores. Este avance tiene mayor calidad cuando se realiza de modo íntegro. 
http://doi.org/10.15359/ree.25-1.24

http://www.una.ac.cr/educare

educare@una.ac.cr

Valga reiterar que la sobrevaloración de determinadas características humanas, en detrimento de otras, limita y reduce la riqueza y diversidad consustancial a la condición humana. La mentalidad tecnocrática atenta contra tales características. Según la concepción pragmática del mundo, que sustenta este tipo de mentalidad, las profesiones existen solo para solucionar problemas instrumentales $y$, se considera, al mismo tiempo, que esta faena debe realizarse con la mayor rigurosidad posible. Desde esta perspectiva, la vía que se concibe como idónea para que haya el rigor que debe caracterizar esta faena es la del empleo exclusivo de la capacidad racional. Según este basamento, la parte afectiva, con su carga subjetiva, enturbia la razón, y atenta contra la objetividad y la precisión.

\section{La categoría condición humana ante la sobrevaloración de la capacidad racional}

El reduccionismo y la fragmentación (también la separación inconexa) en la educación superior se manifiestan, asimismo, en la sobrevaloración de la capacidad racional. La causa fundamental de este fenómeno está en la búsqueda de la objetividad, que, como se vio más arriba, es una de las características esenciales del pensamiento simplificador; se debe a la pretensión de excluir la carga subjetiva para afianzar la objetividad y, con ella, el rigor científico. Se rechaza todo cuanto dependa directamente del sujeto o lleve su impronta, como las valoraciones éticas y los juicios filosóficos. De este modo, se cercena el profesionalismo y así se atenta contra la condición humana.

La estimación exclusiva de la capacidad racional va aparejada al menosprecio de las emociones, los sentimientos, las pasiones, es decir, la afectividad, la cual tiene una importancia básica en la vida humana y también en la educación (Martínez Priego, 2015), de lo que no está ajeno su nivel más elevado. En la educación superior el énfasis recae en el dominio del sistema conceptual de cada asignatura y disciplina, mientras que al plano afectivo se le brindaba menor atención. Esta limitación, según certifican las autoras Ojalvo Mitrany y Curiel Peón (2018), se observa en las carreras pedagógicas, donde el grado de reproducción es elevado porque en ellas se está educando al profesorado del mañana.

El predominio del enfoque intelectualista y la relegación de la afectividad a planos inferiores o nulos inquieta a muchos educadores y educadoras de diversas partes del mundo y de todos los niveles educacionales (Barrantes-Elizondo, 2016; Castañeda Serra, 2014; Curiel Peón et al., 2018; Fernández Domínguez et al., 2009). Si bien este interés crece y aunque el filósofo español Marina (2005) ha afirmado, con ganada autoridad, que la bibliografía en torno a la educación emocional es amplísima, en cuanto a la educación superior no es notoriamente abundante la cantidad de textos dedicados a estudiar estos asuntos, no solo lo emocional, sino también lo afectivo en su integridad. Tal afirmación se puede comprobar con una búsqueda bibliográfica que abarque diversas revistas, de cualquier país, en las cuales pueda haber estudios 
http://doi.org/10.15359/ree.25-1.24

de universos temáticos afines. Esta aseveración se limita al mundo de la lengua española y no niega la existencia de trabajos profundos y actuales, como el de Fragoso-Luzuriaga (2015), el de Curiel Peón et al. (2018) y otros, aun cuando en ellos es notable la concentración de la atención en lo racional, como el de los autores León Castillo et al. (2019).

La educación superior no es una obra fría. Freire (2010) enfatizaba que en todo quehacer educativo debe cuidarse el equilibrio entre lo racional y lo afectivo, pues no es una labor carente de sentimientos y emociones, dominada por la razón, aunque tampoco puede verse como "una experiencia a la que le faltara el rigor que genera la necesaria disciplina intelectual (p. 118). De ahí la recomendación de tomar "en consideración todas las dimensiones afectivas que han sido olvidadas por los discursos científicos y filosóficos tradicionales" (Gonzále Gaona y Fernández Guerrero, 2014, p. 45).

Para bien de la labor teórica y práctica educacional, crece el número de estudios que reconocen que en los vínculos afectivos hay un gran potencial para que sea más eficaz el proceso enseñanza-aprendizaje (Maldonado-Torres et al., 2018). Según el autor Triadó Ivern (2020), en estos tiempos hay dos características muy generalizadas en estudiantado universitario: la fuerza que en cada quien tienen los sentimientos, y que son personas muy emocionales, acostumbradas a cambiar con un clic cuando algo no les interesa y a continuar; por eso, según este autor, el profesorado universitario tiene ante sí el reto de aprender a gestionar las emociones y contribuir con el proceso de su maduración.

En correspondencia con lo anterior, está la afirmación del estudioso Bueno (2020) en cuanto a que "las emociones contribuyen a generar aprendizajes a largo término que sean mucho más eficientes" (104), pues son patrones de conducta preconscientes que se forman ante la necesidad de responder con rapidez, mientras que las respuestas reflexivas son más lentas. Sostiene que el aprendizaje con emociones se fija más en la memoria, sobre todo, si se trata "del miedo, la ira, el asco, la tristeza, la alegría y la sorpresa" (104), aunque puntualiza que la alegría y la sorpresa son las más útiles en la educación; la primera, porque transmite confianza, y se aprende de la persona en quien se confía, pero es poco intensa, por eso no estimula grandes aprendizajes, mientras que la sorpresa, que se puede generar ante una situación inesperada, un cambio de ritmo, una anécdota, contribuye a mantener despierta la atención del alumnado con mayor frecuencia y duración.

Como resultado de la atención a la afectividad y a su conjugación con la razón, en estos tiempos que corren se habla de la inteligencia emocional, es decir, la inteligencia que se fundamenta en las emociones. Esta denominación tomó carta legal porque se llegó a reconocer que la inteligencia es multidimensional y que entre esas dimensiones están la inteligencia intrapersonal y la interpersonal, que son las que constituyen la inteligencia emocional (de los Reyes López y de los Reyes Calvo, 2020). 
http://doi.org/10.15359/ree.25-1.24

http://www.una.ac.cr/educare

educare@una.ac.cr

A partir de la importancia que se le ha dado a la conjugación de la razón y la afectividad, urge en la educación superior fortalecer el componente afectivo y hacerlo como un proceso intencionado, para promover la expresión adecuada de emociones, sentimientos y pasiones e incentivar el autoconocimiento en la interacción en el proceso de enseñanza-aprendizaje y así optimizar esta labor, que, si se mira con profundidad afectiva, es un acontecimiento para celebrar, un tipo de fiesta y por eso debiera disfrutarse. Esto no significa que en la educación superior se pueda prescindir del razonamiento, ni de la rigurosidad que impone la disciplina intelectual. En la educación superior es necesario el equilibrio entre lo racional y lo afectivo. Para ello, el profesorado tiene a su alcance una gran gama de oportunidades y vías para motivar al estudiantado y lograr que se regocije en el proceso de enseñanza aprendizaje. Esta recomendación, válida para todos los tipos de educación, en el nivel superior debe realizarse con la mayor amplitud para evitar que se circunscriba a las necesidades de una carrera o de una profesión específica.

A propósito de lo anterior, vale traer a colación un asunto que debe llamar mucho más la atención, porque puede convertirse en un problema muy serio de la humanidad: la indiferencia. Este fenómeno se deja observar de un modo creciente y de muchas formas, en seres humanos de todas las edades, niveles culturales y estratos sociales; y no se trata específicamente de la indolencia respecto a asuntos individuales ajenos, que alguien puede considerarlos insignificantes o intrascendentes. Lo llamativo y alarmante no está en lo estrictamente concerniente a las relaciones entre dos personas, sino a la insensibilidad ante ideas y hechos denigrantes e inhumanos, como el racismo, la xenofobia y cualquier tipo de discriminación, que son manifestaciones y resultados, en todos los casos, de que no se tiene en cuenta, en su justa medida, que todo humano vale (y mucho) por el simple y elemental hecho de ser un ser humano. A su vez, sobresale la impasibilidad ante lo que desvirtúa o frena el mejoramiento, que debe continuamente escalar peldaños superiores y no limitarse a la moral o a los conocimientos científicos y tecnológicos, sino abarcar todos los ámbitos humanos, como el del cuidado del planeta y la vida, con su diversidad.

La causa fundamental de la apatía no es solo la sociedad posmoderna con su principio de que todo vale, por lo que todo puede suceder, así como el extremo individualismo imperante en ella y su resultado de que nada más vale lo que le interesa a cada cual, sino también y en mucho, la ideología neoliberal, que es esencialmente fatalista, con la cual se pretende convencer a los hombres y a las mujeres de que la vida humana es inmejorable porque es inalterable y por eso debe vivirse el presente como sea, e ignorarse el mañana, que de alguna manera llegará (Freire, 2010). Como consecuencia, desaparece, o por lo menos, disminuye la importancia del prójimo y la atención solo recae sobre la propia persona. A su vez, se engendra pasividad y resignación, y no solo eso, sino porque el mejoramiento humano se muestra como un absurdo, en torno al cual no amerita pensar. 
http://doi.org/10.15359/ree.25-1.24

Una herramienta para enfrentar la indolencia en la educación superior es la estimulación a que sus estudiantes desarrollen el pensamiento crítico. Para realizar este objetivo, el profesorado debe darles la oportunidad de contactar con variados contenidos docentes, sobre todo teorías sociales (García García, 2018), para reflexionar en torno a las sociedades que se han edificado con esas teorías y criticarlas, que no es negarlas, ni censurarlas, sino reflexionar en torno a lo positivo y negativo que contienen; para tratar de resolver problemas; para pensar en la construcción de una sociedad donde el ser humano valga simplemente porque es un ser humano y no haya discriminación por nada: color de la piel, lugar de nacimiento, preferencias, pareceres.

Pudiera preguntarse de qué manera la educación superior puede integrar la concepción compleja acerca del ser humano y la arendtiana de la condición humana. Puede ubicarse a ambas en la base misma de la comprensión de la educación superior y desde aquí, conjugadas, estar presentes en todas sus manifestaciones, y guiarlas con la riqueza que proporcionan la diversidad y las contradicciones. De la creatividad y valentía de cada docente, dependerá, en gran medida, que sus estudiantes se transformen en profesionales que abarquen mucho más de la profesión y que en su comportamiento esté la calidez de la afectividad y la firmeza de la razón. Vale arriesgarse, sobre todo en un mundo como este, donde la humanidad no ha llegado aún a la mitad del siglo XXI y ya anda desenfrenada por arribar a la vigésima segunda centuria.

\section{Conclusiones}

Un gran desafío para la educación superior en la actualidad es atender, en una medida justa, las características y necesidades cada vez más varadas y difíciles de la sociedad y la cultura. De ahí que urge concebirla de un modo complejo, es decir, con toda la trama de relaciones en las cuales se desarrolla y con las que tienen lugar en su interior. Una vía para lograrlo es tener presente la categoría condición humana. El empleo del pensamiento complejo en la educación superior y el despliegue en ella de la visión integradora posibilita concebir al estudiantado de manera integrada, sin sobrevalorar ninguna característica.

La categoría condición humana destaca la integración entre el ser humano y lo que hace posible que este exista y se desarrolle. Su esencia se corresponde con la del pensamiento complejo, porque les son consustanciales el elevado grado de relaciones.

La intención de lograr que la educación superior se despliegue de manera multilateral y armónica es una exigencia de la sociedad actual, particularmente del desarrollo de la ciencia y la tecnología, que demanda profesionales que no solo dominen la especialidad.

La observación de la educación superior desde la perspectiva mercantil y empresarial es la causa fundamental de la sobrevaloración de las competencias y habilidades profesionales 
http://doi.org/10.15359/ree.25-1.24

http://www.una.ac.cr/educare

educare@una.ac.cr

y de ignorar otros aspectos, como la formación ciudadana. La educación superior debe moldear todas las capacidades y facultades del alumnado, y así avanzar en el difícil camino del mejoramiento humano.

En la educación superior es preciso brindarle mayor atención a la afectividad, pero esto no puede entenderse de manera maniquea, que se descuide la capacidad racional y se haga de la afectividad el centro regidor del quehacer educacional en su más elevado nivel. Lo que se necesita es el equilibrio entre ambas y que se aprecien con justicia.

La visión integradora es de suma importancia en la educación superior, entre otras, por las causas siguientes: es un contén para impedir que se privilegie la formación de cualidades laborales, profesionales y se releguen a planos secundarios o se ignoren, otros componentes de la educación superior, como el ético y el estético; tiene una potencia todavía no justipreciada para que rebase el racionalismo empedernido y se abra a la afectividad; es una vía para educar profesionales quienes, con su capacidad racional y su riqueza afectiva, se interesen por los problemas actuales de la sociedad y por aquellos que pueden incrementarse en un futuro cercano, como es la indiferencia, ante todo respecto al mundo donde se vive y al mejoramiento humano.

\section{Recomendaciones}

Urge debatir en torno a otras separaciones existentes en la educación superior: entre las áreas del saber; entre la teoría y la práctica, las personas dirigentes y las dirigidas, las pensantes y las ejecutivas, así como entre la educación y la instrucción, el profesorado y el alumnado. Atender que estas separaciones se tornan esquemáticas porque se olvida que la condición humana es una totalidad compleja, poseedora de una inimaginable diversidad que se muestra mediante contradicciones y consonancias, afirmaciones y negaciones, en cada individuo, en la sociedad y en los nexos entre ambos.

\section{Declaración de Material complementario}

Este artículo tiene disponible, como material complementario:

-La versión preprint del artículo en https://doi.org/10.5281/zenodo.3534615 


\section{Referencias}

Aldana Contardi. L. (2012). Función utópica y condición humana. Inflexiones a partir de los trazos de Arturo Andrés Roig. Cuyo. Anuario de Filosofía Argentina y Americana, 29(2), 85-105 https://ri.conicet.gov.ar/bitstream/handle/11336/37238/CONICET_Digital_ Nro.73121a6e-5129-44a0-a5af-4d12d25173f5 A.pdf?sequence=2\&isAllowed=y

Andrés Roig, A. (2003). La condición humana: Desde Demócrito hasta el Popol Vuh. Literatura y Lingüística, 14, 1-16. https://www.redalyc.org/pdf/352/35201417.pdf

Ardila-Muñoz, J. Y. (2016). Movilidad estudiantil: Entre la intención de integración de la educación superior y su mercantilización. Quaestiones Disputatae, 9(18), 89-109. http:// revistas.ustatunja.edu.co/index.php/qdisputatae/article/view/1044

Arendt, H. (2005). La condición humana. Paidós.

Ávila Alexander, R. (2015). El dispositivo de formación cívica y ética desde los planteamientos de Michel Foucault: Prácticas y discursos en la División Académica de Educación y Artes de la UJAT (2012-2014). Uni-pluri/versidad, 15(1), 100-110. https://dialnet.unirioja.es/servlet/ articulo?codigo $=7580449$

Barrantes-Elizondo, L. (2016). Educación emocional: El elemento perdido de la justicia social. Revista Electrónica Educare, 20(2), 1-10. http://dx.doi.org/10.15359/ree.20-2.24

Barrio, C. (2015). La función del pensamiento y el discurso en Hannah Arendt. De los juicios reflexivos a los juicios políticos. Ideasy Valores, 64(159), 109-130.http://dx.doi.org/10.15446/ ideasyvalores.v64n159.41567

Bermúdez-Aponte, J. J. y Laspalas Pérez, F. J. (2017). El profesor universitario: Integración entre lo personal y lo profesional. Teoría de la Educación. Revista Interuniversitaria 29(2), 109-126. http://dx.doi.org/10.14201/teoredu292109126

Brower Beltramin, J. (2014). Reflexiones en torno a la re-afirmación del sentido de la universidad. Revista Internacional de Investigación en Ciencias Sociales, 10(2), 213-229. http:// revistacientifica.uaa.edu.py/

Billitteri, S. (2018). Hannah Arendt lectora de Franz Kafka: Una mirada pedagógica a la razón poética. Teoría de la educación. Revista Interuniversitaria, 30(1), 117-132. http://dx.doi. org/10.14201/teoredu301117132 
http://doi.org/10.15359/ree.25-1.24

http://www.una.ac.cr/educare

educare@una.ac.cr

Bueno, D. (2020). 5. Conocimientos neurocientíficos aplicados a la educación. En M. Turull (Coord.), Manual de docencia universitaria (pp. 99-107). Octaedro. https://octaedro.com/ libro/manual-de-docencia-universitaria/

Castañeda Bustamante, H. (2018). La paradoja simplificadora del discurso del pensamiento complejo. Encuentros, 16, 170-182 https://dialnet.unirioja.es/servlet/ articulo?codigo $=6662639$

Castañeda Serna, C. M. (2014). Competencia socioafectiva en el marco escolar colombiano. Escenarios, 12(2), 19-34 http://dx.doi.org/10.15665/esc.v12i2.312

Comesaña Santalices, G. y Cure de Montiel, M. (2006). El pensamiento como actividad según Hannah Arendt. Utopía y Praxis Latinoamericana, 11(35), 11-30. http://ve.scielo.org/scielo. php?script=sci arttext\&pid=S1315-52162006000400002\&lng=es\&nrm=iso

Cuadra-Martínez, D. J. Castro, P. J. y Juliá, M. T. (2018). Tres saberes en la formación profesional por competencias: Integración de teorías subjetivas, profesionales y científicas. Formación Universitaria, 11(5), 19-30. http://dx.doi.org/10.4067/S0718-50062018000500019

Curiel Peón, L., Ojalvo Mitrany, V. y Cortizas Enríquez, Y. (2018). La educación socioafectiva en el proceso de enseñanza aprendizaje. Revista Cubana de Educación Superior, 37(3), 80-92. $\quad$ http://scielo.sld.cu/scielo.php?script=sci arttext\&pid=S0257$43142019000100010 \& \operatorname{lng}=e s \& t \operatorname{lng}=$

de los Reyes López, E. y de los Reyes Calvo, S. (2020). 8. Las relaciones humanas del profesorado con los estudiantes y el entorno docente. En M. Turull (Coord.), Manual de docencia universitaria (pp. 147-161). Octaedro. https://octaedro.com/libro/manual-de-docenciauniversitaria/

Descartes, R. (2011). Discurso sobre el método que ha de seguir la razón para buscar la verdad en las ciencias. En R. M. Buch Sánchez (Ed.), Antología Historia de la Filosofía (tomo 3, pp. 160-164). Editorial Félix Varela.

Fernández Domínguez, M. R., Palomero Pescador, J. E. y Teruel Melero, M. P. (2009). El desarrollo socioafectivo en la formación inicial de los maestros. REIFOP, 12(1), 33-50. https://dialnet. unirioja.es/descarga/articulo/2956687.pdf 
http://doi.org/10.15359/ree.25-1.24

Ferrada-Sullivan, J. (2017). Reflexiones preliminares para pensar la formación de formadores en la universidad moderna: Nuevas miradas y nuevos diálogos desde la complejidad. Revista Electrónica Educare, 21(2), 1-17. https://doi.org/10.15359/ree.21-2.21

Fragoso-Luzuriaga, R. (2015). Inteligencia emocional y competencias emocionales en educación superior, ¿un mismo concepto? RIES. Revista Iberoamericana de Educación Superior, 6(16), 110-125. https://doi.org/10.22201/iisue.20072872e.2015.16.154

Freire, P. (2010). Pedagogía de la autonomía y otros textos. Editorial Caminos.

García García, J. J. (2018). ¿Para qué educar? [Editorial]. Uni-pluri/versidad, 18(1), 11-12. https:// doi.org/10.17533/udea.unipluri.18.1.01

García Mazo, C. M. (2018). La mercantilización de la educación superior en Colombia. Educación y Humanismo, 20(34), 36-58. http://dx.doi.org/10.17081/eduhum.20.34.2857

Goicoechea Gaona, M. Á. y Fernández Guerrero, O. (2014). Filosofía y educación afectiva en Amor y pedagogía, de Unamuno. Teoría de la Educación. Revista Interuniversitaria, 26(1), 41-58. http://dx.doi.org/10.14201/teoredu20142614158

González Rivero, B. M. (2019). Retos de la formación ciudadana para la educación superior. Universidad y Sociedad, 11(4), 341-349. https://rus.ucf.edu.cu/index.php/rus/article/ view/1311/1342

Guadarrama González, P. (2018). Para qué sirve la epistemología a un investigador y un profesor. Magisterio Editorial.

Güechá Hernández, J. F. (2018). Reseña al libro La universidad de la ignorancia. Capitalismo académico y mercantilización de la educación superior, por R. Vega Cantor. Literatura: Teoría, Historia, Crítica, 20(2), 353-361. http://dx.doi.org/10.15446/lthc.v20n2.70343

Korstanje, M. (2014). El miedo político bajo el prisma de Hannah Arendt. Revista SAAP. Publicación de Ciencia Política de la Sociedad Argentina de Análisis Político, 8(1), 99-126. http://www. redalyc.org/articulo.oa?id=387136369004

León Castillo, Y., Reiné Herrera, Y., \& Charbonell Martel, M. E. (2019). Una mirada a la formación de profesionales universitarios que demanda el siglo XXI en Cuba. Revista Cubana de Educación Superior, 38(1), 1-13. http://www.rces.uh.cu/index.php/RCES/article/view/262/304 
http://doi.org/10.15359/ree.25-1.24

http://www.una.ac.cr/educare

educare@una.ac.cr

Luengo González, E. (2016). El conocimiento complejo. Método-estrategia y principios. En L. G. Rodríguez Zoya (Coord.), La emergencia de los enfoques de la complejidad en América Latina. Desafíos, contribuciones y compromisos para abordar los problemas complejos del siglo XXI (tomo I, capítulo 2, Colección Pensamiento Complejo del Sur, pp. 61-82). Comunidad Editora Latinoamericana.

Llerena Companioni, O. (2015). El proceso de formación profesional desde un punto de vista complejo e histórico-cultural. Revista Actualidades Investigativas en Educación, 15(3), 1-23 http://dx.doi.org/10.15517/aie.v15i3.21041

Maldonado, C. E. (Ed.). (1999). Visiones sobre la complejidad. El Bosque.

Maldonado-Torres, S., Araujo, V. y Rondon, O. (2018). Enseñar como un "acto de amor" con métodos de enseñanza-aprendizaje no tradicionales en los entornos virtuales. Revista Electrónica Educare, 22(3), 1-12. http://dx.doi.org/10.15359/ree.22-3.18

Marina, J. A. (2005). Precisiones sobre la educación emocional. Revista Interuniversitaria de Formación del Profesorado, 19(3), 27-43 http://www.redalyc.org/articulo. oa?id=27411927003

Martínez Priego, C. (2015). Urdimbre afectiva y educación. Aproximación a las ideas pedagógicas de Juan Rof Carballo. Estudios sobre Educación, 28, 139-154. https://doi. org/10.15581/004.28.139-154

Monge Ortiz, J. A. (2020). El propósito de la formación humanista en la Universidad de Costa Rica del siglo XXI. Revista Estudios, (1-15 https://revistas.ucr.ac.cr/index.php/estudios/ article/view/40924/41536

Morin, E. (1999). Los siete saberes necesarios para la educación del futuro. UNESCO.

Morin, E. (2002). La cabeza bien puesta. Repensar la reforma. Reformar el pensamiento. Ediciones Nueva Visión.

Nieves Loja, G. M. (2017). Hannah Arendt y el problema de la educación. Sophia: Colección de Filosofía de la Educación, 23(2), 219-235. http://doi.org/10.17163/soph.n23.2017.08

Ojalvo Mitrany, V. y Curiel Peón, L. (2018). La tradición humanista de la educación cubana: Premisa para la formación docente en educación socioafectiva. Atenas, 3(43), 118-131. https://www.redalyc.org/articulo.oa?id=478055153008 
http://doi.org/10.15359/ree.25-1.24

http://www.una.ac.cr/educare educare@una.ac.cr

Pallarès Piquer, M. y Muñoz Escalada, M. C. (2017). La vigencia de Hannah Arendt y John Dewey en la acción docente del siglo XXI. Foro de Educación, 15(22), 1-23. http://www.redalyc.org/ articulo.oa?id=447549523009

Riechmann, J. (2014). Acerca de la condición humana. En A. Diéguez y J. M. Atencia (Eds.), Naturaleza animal y humana (pp. 229-266). Biblioteca Nueva.

Triadó Ivern, X. M. (2020). Prólogo. En M. Turull (Coord.), Manual de docencia universitaria (pp. 1122). Octaedro. https://octaedro.com/libro/manual-de-docencia-universitaria/

Wee, C. y Monarca, H. (2019). Educación superior en contextos de cuasi mercados. Educación XX1, 22(1), 117-138. https://repositorio.uam.es/bitstream/handle/10486/689050/educacion wee EXXI 2019.pdf?sequence $=1$

Zapata, G. (2006). La condición política en Hannah Arendt. Papel Político, 11(2), 505-523. http://www.scielo.org.co/scielo.php?pid=S0122-44092006000200002\&script=sci_ arttext\&tlng=pt 